\title{
De geneeskundestudent \& de patiënt-student: inductie van empathie
}

\author{
M.J. Gosselink, E.M. van Fenema
}

\section{Samenvatting}

In het medisch onderwijs verdient de ontwikkeling van empathie en professioneel gedrag een prominente plaats. Het creëren van empathie voor mensen met een psychiatrische aandoening is een extra uitdaging. Veel medisch studenten hebben stigmatiserende vooroordelen over psychiatrische patiënten. Dit is zorgelijk, alleen al omdat ze later als arts allen te maken zullen krijgen met patiënten, maar ook eventueel met collegae, die psychiatrisch bekend zijn. Vooroordelen komen de arts-patiëntrelatie en medische zorg niet ten goede. Dit artikel schetst de mogelijke impact van het lijden aan een psychiatrische aandoening op een student; daaraan gekoppeld presenteren wij een onderwijsopzet met als doel de empathiekloof tussen aanstaande dokters en mensen met psychiatrische aandoeningen te verkleinen. (Gosselink MJ, Fenema EM van. De geneeskundestudent \& de patiënt-student: inductie van empathie. Tijdschrift voor Medisch Onderwijs 2011;30(1-2):22-27)

\section{Inleiding}

Empathie is van groot belang voor de professionele arts-patiëntrelatie. Uit onderzoek komt naar voren dat de mate van empathie bij medisch studenten in de loop van de studie daalt. Hiervoor worden diverse oorzaken genoemd, welke uiteenlopen van weinig patiëntcontacten en het gebrek aan goede rolmodellen tot hoge studiebelasting. ${ }^{1-4}$ In het medisch onderwijs verdient de ontwikkeling van empathie en professioneel gedrag een prominente plaats. Hiertoe zijn velerlei opties, variërend van gesprekken met artsen en patiënten, tot opname in een artificiële ziekenhuissetting en rollenspellen. ${ }^{5-6}$

Het creëren van empathie voor mensen met een psychiatrische aandoening is een extra uitdaging. Veel medisch studenten hebben stigmatiserende vooroordelen over psychiatrische patiënten. ${ }^{7-10}$ Dit is zorgelijk omdat ze later als arts allen te maken zullen krijgen met patiënten die naast de somatische problematiek, ook psychiatrische aandoeningen hebben. Ook kunnen ze moge- lijk samenwerken met collegae met een psychiatrische aandoening. Vooroordelen komen de arts-patiëntrelatie en de medische zorg niet ten goede. Empathie voor psychiatrische patiënten kan bij de medisch student onder andere vergroot worden door hem/haar met psychiatrische patiënten in contact te brengen of hem/haar te laten reflecteren op aan psychiatrie gelieerde literaire fictie of speelfilms. ${ }^{10-16}$ Aangaande de eerste optie blijkt de empathiekloof groter naarmate de patiënt als persoon verder van de student afstaat. ${ }^{7-11}$ Onze hypothese is dat we deze kloof deels kunnen overbruggen door ervaringsdeskundigen in te zetten waarmee de student zich qua leeftijd en omstandigheden kan identificeren.

Doel van dit artikel is een beschrijving te geven van de impact van een bipolaire stoornis op het leven van een student. Daaraan gekoppeld presenteren we een onderwijsopzet met als doel bovenstaande empathiekloof te verkleinen.

Voor een 'interactiemiddag' werden vijf coassistenten die hun coschap psychiatrie 
liepen uitgenodigd en Floris (zie Casus), een conservatoriumstudent die lijdt aan een bipolaire stoornis. Floris wordt voor zijn psychiatrische aandoening begeleid op de 'Muziekpoli' van het Leids Universitair Medisch Centrum (LUMC).

\section{Format interactiemiddag}

Van tevoren bestudeerden de coassistenten de diagnostiek en behandeling van de bipolaire stoornis (zie Box 1). Eén coassistent bereidde tevens over de bipolaire stoornis een presentatie voor. Zijn ondersteunende diapresentatie werd tevoren door Floris met zijn psychiater doorgenomen. Bij de interactiemiddag waren de vijf coassistenten, Floris, Floris' psychiater $(\mathrm{EvF})$ en docerend psychiater (MG) aanwezig.

Box 1. De bipolaire stoornis.

Kenmerkend voor een bipolaire of manisch depressieve stoornis zijn afwisselende episoden met heftige en extreme gemoedstoestanden. De stemming kan gedurende een periode somber (depressief) of juist heel uitgelaten en vrolijk (manisch) zijn. Een manische fase wordt gekenmerkt door een abnormaal vrolijke en/of geprikkelde stemming, een overmatig gevoel van eigenwaarde en een afgenomen slaapbehoefte. $\mathrm{Er}$ is sprake van spreekdrang, slechte concentratie door verhoogde afleidbaarheid en een snelle gedachtegang. Tijdens een manische episode is er een toename van doelgerichte activiteit, bijvoorbeeld het opzetten van in de realiteit niet haalbare projecten (welke op zich verrassend creatief kunnen zijn), bijvoorbeeld op het gebied van studie of onderzoek. Ook kan er sprake zijn van onverantwoord (grensoverschrijdend of seksueel) gedrag, het doen van zakelijk onverstandige investeringen of ongeremde koopwoede. Een en ander leidt begrijpelijkerwijs uiteindelijk tot fysieke uitputting en kan op divers sociaal-maatschappelijk vlak ernstige gevolgen hebben.

\section{Het onderwijsprogramma}

- 13.30-14.00 uur: Introductie door beide psychiaters. Kort voorstelrondje.

- 14.00-14.30 uur: De coassistent houdt voor het hele gezelschap zijn presentatie.

- 14.30-15.15 uur: Floris illustreert, aan de hand van de dia's die de coassistent ook gebruikte, de diverse symptomen met zijn persoonlijke ervaringen. De coassistenten stellen hem hierbij tussendoor vragen.

- 15.30- \pm 17.00 uur: Rondetafel gesprek met Floris en de coassistenten.

\section{Verloop van het gesprek}

Het gesprek verliep op open, ontspannen wijze en was vol humor. Structurering door de psychiaters bleek nauwelijks nodig. Allereerst vertelde ieder persoonlijk iets over zijn/haar achtergrond. Zowel Floris als de coassistenten waren van dezelfde leeftijd en hadden diverse raakvlakken. Zo was bijvoorbeeld rond studie-ervaringen, hobby's en professionele passie wederzijdse herkenning. Ook waren er overeenkomsten op het gebied van activiteiten, favoriete cafés, middelbare school, etc. Vervolgens spraken ze over de bipolaire stoornis. Floris vertelde over de invloed van de aandoening op zijn persoon en omstandigheden. Er werd gesproken over stigmatisering. Er ontstond een indrukwekkend gesprek over de onzekerheden en levensvragen waar alle betrokkenen in deze levensfase tegenaan lopen. Hierbij was evident begrip voor de extra kwetsbaarheid van Floris. Ook de grens tussen bijvoorbeeld de manie en 'enthousiasme', 'creativiteit' of 'gewoon een keer hyper zijn' kwam aan bod. Coassistenten benoemden hun eigen 'ups' en 'downs'. Floris vergeleek die met zijn 'ups' en 'downs', maar ook met zijn manieën en depressies. Eén van de coassistenten vertelde zelf ook twee jaar geleden een depressie te hebben doorgemaakt. 
In de discussie kwam het belang van een goede arts-patiëntrelatie bij de diagnostiek en behandeling aan bod, evenals de moeilijkheden die een arts kan tegenkomen bij het opbouwen van een band met zijn/haar patiënt en andersom. Zowel Floris als de coassistenten noemden voorbeelden. Floris noemde diverse 'do's en don'ts'. Hij vertelde over zijn eigen aanvankelijke gebrek aan ziektebesef, waardoor hij zijn psychiater op afstand hield. Hij legde uit wat hij een prettige benadering vond met voorbeelden. Dit kon door zijn aanwezige behandelaar worden toegelicht.

\section{Evaluatie van de middag met de coassistenten}

Daags na de bijeenkomst werd ter reflectie een nabespreking georganiseerd. Alle coassistenten waren enthousiast over de middag. De presenterende coassistent vond het houden van een presentatie in aanwezigheid van een patiënt leerzaam. Zowel hij als zijn collegae erkenden dat zij gedurende de presentatie zeer alert waren geweest of richting Floris het verhaal wel 'tactvol' werd gebracht. Floris' persoonlijke toelichting werd als zeer leerzaam ervaren. Het praten over een ziekte met een 'zieke' leeftijdsgenoot brengt volgens de coassistenten twee belangrijke aspecten met zich mee. Allereerst ervoeren ze een laagdrempeligheid in het aansluiten bij Floris' emoties en cognities. Zij konden zich met hem identificeren, waardoor zij goed in konden voelen wat hij doormaakt. Het empathisch reflecteren verliep volgens hen hierdoor vanzelfsprekender. Daarnaast viel ze ook op dat het 'makkelijk inleven' in Floris' omstandigheden hen ook confronteert met hun eigen kwetsbaarheid als mens. De veilige afstand die zij ervaren als zij te maken hebben met een patiënt van geheel andere leeftijd en/of levensomstandigheden valt nu weg. Het peer-contact is indringend. Het biedt naar hun mening veel grond voor reflectie. Zij dachten naar aanleiding hiervan ook meer empathie voor patiënten met een vergelijkbare aandoening van andere leeftijd en/of levensomstandigheden te ontwikkelen.

\section{Beschouwing}

Uit de beschrijving van Floris' studieproblematiek blijkt de impact die een psychiatrische aandoening, in zijn situatie een nog onvoldoende behandelde bipolaire stoornis, op de studie kan hebben. Floris is conservatoriumstudent. Uit de interactiemiddag kwam naar voren dat de confrontatie met een patiënt in een vergelijkbare levensfase de student raakt. Door bij eerste patiëntcontacten aan te sluiten bij de eigen (belevings)wereld van de student, wordt mogelijk op directer en indringender wijze een appèl gedaan op het empathisch vermogen. Uiteraard hechten wij ook belang aan de confrontatie met patiënten in andere levensfasen en/of omstandigheden.

Echter, de confrontatie met juist een zieke van dezelfde leeftijd is zowel op emotioneel als cognitief vlak extra indringend. Niet alleen in het coschap psychiatrie, maar ook in andere klinische stages kan een peer contact onzes inziens van meerwaarde zijn. In de praktijk blijkt het structureel inroosteren van een dergelijk reflectieve middag in ons coschap niet haalbaar, aangezien er dan ook op frequente basis een leeftijdgenoot van de coassistenten bereid moet zijn zijn of haar ervaringen met de groep te delen. Voor Floris bijvoorbeeld is begrijpelijkerwijs een 6-wekelijkse inroostering in het coschap psychiatrie zowel emotioneel als praktisch niet acceptabel. Een optie is een korte documentaire over de levenssituatie van een peer te maken, eventueel gekoppeld aan een opgenomen videosessie van 
een interactiemiddag. Deze zou structureel kunnen worden getoond en worden gevolgd door een rondetafelgesprek tussen de coassistenten. Maar zelfs zonder documentaire beschouwen wij reflectieve sessies, waarbij de docent de coassistenten uitdaagt zich in te leven in de situatie van een zieke peer, van grote meerwaarde voor de groei van empathie en professionaliteit.

\section{Casus}

"Als ik niet meer kan spelen dan hoeft het voor mij niet meer" zegt Floris. "Muziek betekent alles voor mij, het is mijn moedertaal!".

Floris is een conservatoriumstudent van 24 jaar en een groot pianotalent. De laatste weken gaat het niet goed met hem. Hij is onrustig, prikkelbaar en lijkt soms zichzelf niet te zijn. Hij is meer dan ooit bezig met pianospelen. Hij heeft het gevoel dat hij als enige begrijpt wat Mozart wilde zeggen met zijn pianoconcerten. Nachtenlang is hij in de weer met partituren en hij heeft ook energie om 's nachts door te studeren. Dit leidt uiteraard tot veel ergernis bij zijn huisgenoten. Al met al slaapt hij de laatste week maar een paar uur per nacht zonder echt moe te zijn. Zijn pianospel is echter de laatste tijd onder de maat. Hij is hierop niet aan te spreken zonder dat hij in woede ontsteekt. Als hij op les komt is hij het regelmatig op luidruchtige wijze oneens met zijn hoofdvakdocent piano. Zo heeft hij tijdens de les een keer de klep van de vleugel hard dichtgeslagen en zijn leraar uitgemaakt voor 'amateur'. Sindsdien hoeft hij niet meer op les te komen. Voor het vak muziekgeschiedenis moest hij een werkstuk maken. Hij koos voor Mozart en de vrijmetselarij. Bladzijden vol schreef hij over de Broederschap en hoe het collectief de mensheid op een hoger plan kan brengen. Inmiddels volgt hij zijn bijvakken niet meer: "dat is voor ambtenaren" vindt hij. Zijn medestudenten vinden hem flamboyant, grappig en zijn tomeloze energie is inspirerend. Maar zijn recente onrust en prikkelbaarheid maken hen ongerust. Dit is 'over the top'. Floris is bezig met allerlei projecten. Zo wil hij met het schoolorkest een Mozart-marathon houden: alle 27 pianoconcerten achter elkaar uitvoeren tijdens een speciale Mozart-nacht. Ook wil hij een project klassieke muziek gaan opzetten in de sloppenwijken van Rio de Janeiro.

Floris is naar mij (EvF) verwezen door de huisarts omdat de toenemende conflicten, de achterblijvende studieprestatie en het nauwelijks meer slapen redenen tot zorg zijn. De huisarts heeft Floris al eerder verwezen naar een psychiater toen hij een periode erg neerslachtig was en nauwelijks zijn bed uitkwam, maar Floris is nooit gegaan. Floris is nu schoorvoetend akkoord gegaan met de doorverwijzing naar de Muziekpoli (zie Box 2); het leek hem wel interessant om met een 'expert' van gedachten te wisselen over de geestesgesteldheid van Mozart toen deze zijn Requiem componeerde.

Ik zie een magere jongeman met indringende bruine ogen en een verwarde bos bruine krullen, die een openhangende donkerrode blouse draagt. Hij vertelt druk gesticulerend zijn verhaal, is moeilijk te onderbreken en springt van de hak op de tak. Als ik opmerk dat hij wel erg intensief met Mozart bezig is antwoordt hij: "die intensiteit is precies de overeenkomst tussen Mozart en mij, wij hebben in feite een overeenkomst gesloten op kosmisch niveau. In de naam Mozart zit al het woord 'art', kunst!"

Floris is manisch, waarschijnlijk in het kader van een bipolaire stoornis. Hij heeft op dit moment weinig besef dat hij lijdt aan een psychiatrische ziekte. Voorzichtig probeer ik hem te laten nadenken over de 
vraag of zijn recente gedrag pure artistieke bevlogenheid is of dat we toch te maken hebben met een stoornis die uiteindelijk zijn artistiek functioneren juist belemmert. Deze vraag maakt hem opeens stil, maar na een paar seconden veert hij op en zegt: "ach, sommige mensen dachten ook dat Mozart gek was, misschien is dat wel de prijs voor een briljante geest!" Wat hij wel erkent, is dat hij te weinig slaapt. Ook al voelt hij zich erg fit, hij begrijpt dat 'de koek op een dag op is'. Ook beaamt hij de feiten: dat hij veel conflicten heeft en dat zijn studie gevaar loopt. En muziek betekent nou eenmaal alles voor hem.

Ik kan hem overtuigen dat hij medicatie moet gaan gebruiken om weer normaal te

Box 2. De Muziekpoli van het LUMC.

Het Leids Universitair Medisch Centrum (LUMC) heeft op de afdeling Psychiatrie een polikliniek bedoeld voor podiumkunstenaars die last hebben van psychische klachten: "De Muziekpoli LUMC".

De disbalans tussen psychosociale druk en belastbaarheid van podiumkunstenaars leidt regelmatig tot fysieke en psychische klachten. Dit kunnen klachten zijn zoals podiumangst, depressiviteit, angsten, stress, gevoelens van leegheid en onzekerheid. Deze aandoeningen hebben op hun beurt weer een negatieve wisselwerking op elkaar, op het ontstaan van lichamelijke klachten en op het algemeen en beroepsmatig functioneren. Uit onderzoek komt naar voren dat het taboe bij podiumkunstenaars over lichamelijke blessures langzamerhand afneemt, maar dat psychische klachten moeilijk bespreekbaar zijn en vaak worden weggestopt.

Op de gespecialiseerde Muziekpoli LUMC wordt aandacht besteed aan de psychische problematiek bij podiumkunstenaars. De polikliniek dient meerdere doelen tegelijkertijd: het doorbreken van het taboe op psychische klachten, preventie, tijdige signalering, diagnostiek en behandelingsadvies, onder andere gericht op medicatie, studie en werk. gaan slapen en minder prikkelbaar te zijn. Dat medicatie zijn studie alleen maar ten goede kan komen, ziet hij ook wel in. We spreken voor over een week weer af. We moeten goed in de gaten houden of hij geen last krijgt van bijwerkingen die zijn spel en studie negatief beïnvloeden.

Een week later danst Floris weer mijn spreekkamer binnen. Hij heeft onder zijn arm een tas met boeken en knipsels. “... je wilt niet weten wat ik allemaal heb gevonden..." barst hij los. "Je suggereerde het vorige keer al, maar volgens mij ben ik een beetje manisch of zo, hè??”. Zonder op mijn reactie te wachten gaat hij verder: “... ja, manisch hoort bij manisch depressief en depressief ben ik ook geweest. Ik heb zitten zoeken en echt heel grote geesten hebben daar last van gehad: Schumann, van Gogh, Virginia Woolf, Nina Simone, Edgar Allan Poe, moet ik doorgaan?"

In de loop van de weken blijkt dat de medicatie zonder teveel bijwerkingen aanslaat. Floris functioneert weer als vanouds. We hebben een aantal gesprekken waarin thema's rond acceptatie, lifestyle en valkuilen aan bod komen. Floris is zich ervan bewust dat hij zijn talent alleen kan verwezenlijken als hij rekening houdt met "de demonen die Don Giovanni elk moment naar de hel kunnen sleuren" zoals hij met een grijns besluit.

\section{Literatuur}

1. Hojat M, Vergare MJ, Maxwell K, Brainard G et al. The devil is in the third year: a longitudinal study of erosion of empathy in medical school. Acad Med 2009;84(9):1182-1191.

2. Newton BW, Barber L, Clardy J, Cleveland E, O'Sullivan P. Is there a hardening of the heart during medical school? Acad Med 2008;83(3):244249.

3. Roh MS, Hahm BJ, Lee DH, Suh DH. Evaluation of empathy among Korean medical students: a cross-sectional study using the Korean version of the Jefferson scale of physician empathy. Teaching and Learning in Medicine 2010;22(3):167171. 
4. Chen D, Lew R, Hershman W, Orlander J. A crosssectional measurement of medical student empathy. J Gen Intern Med 2007;22(10):1434-8.

5. Stepien KA, Baernstein A. Educating for empathy - a review. J Gen Intern Med 2006;21:524-530.

6. Hojat M. Ten approaches for enhancing empathy in health and human services culture. J Health Hum Serv Adm 2009;31(4):412-450.

7. Mukherjee R, Fialho A, Weijtetunge A et al. The stigmatisation of mental illness: the attitudes of medical students and doctors in a London teaching hospital. Psych Bull 2002;26(5):178-181.

8. Fernando SM, Deane FP, McLeod HJ. Sri Lankan doctors' and medical undergraduates' attitudes toward mental illness. Soc Psychiat Epidemiol 2010;45(7):733-739.

9. Cutler JL, Harding KJ, Mozian SA, Wright LL, Pica AG, Masters SR, Graham MJ. Discrediting the notion "working with crazies will make you 'crazy': addressing stigma and enhancing empathy in medical student education. Adv in Health Sci Educ 2009;14(4):487-502.

10. Dixon RP, Roberts LM, Lawrie S, Jones LA, Humphreys S. Medical student's attitudes to psychiatric illness in primary care. Med Educ 2008;42:1080-1087.

11. Rasoal C, Jungert T, Hau S, Edvardsson Stiwne E, Andersson G. Ethnocultural empathy among students in health care education. Evaluation and the Health Professions 2009;32(3):300-313.

12. Arvaniti A, Samakouri M, Kalamara E et al. Health Service staff's attitudes towards patients with mental illness. Soc Psychiatry Epidemiol 2009;44(8):658 Published online 12 Dec. DOI:10.1007/s00127-008-0481-3.

13. Ay P, Save D, Fidanoglu O. Does stigma concerning mental disorders differ through medical education? A survey among medical students in
Istanbul. Soc Psychiatry Psychiatr Epidemiol 2006;41(1):63-67.

14. Baxter H, Singh SP, Standen P et al. The attitudes of 'tomorrows doctors' towards mental illness and psychiatry: changes during the final undergraduate year. Med Educ 2001;35(4):381-383.

15. Walters K, Raven P, Rosenthal J, Rusell J, Humphrey C, Buszewicsz M. Teaching undergraduate psychiatry in primary care: the impact on student learning and attitudes. Med Educ 2007;41(1):100-8.

16. Hudson Jones A. Literature and medicine: narratives of mental illness. The Lancet 1997;350:359361.

\author{
De auteurs: \\ Mevr. dr. M.J Gosselink is psychiater en binnen de op- \\ leiding Geneeskunde voorzitter van de Commissie Pro- \\ fessioneel Gedrag LUMC. * \\ Mevr. drs. E.M. van Fenema is psychiater en professio- \\ neel violiste.* \\ * Beiden zijn werkzaam in het Leids Universitair Me- \\ disch Centrum.
}

\begin{abstract}
Correspondentieadres:
Mw. dr. M.J Gosselink, Polikliniek Psychiatrie, Leids Universitair Medisch Centrum, postbus 9600, 2300 RC Leiden.E-mail:m.j.gosselink@lumc.nl
\end{abstract}

\author{
Belangenconflict: geen gemeld \\ Financiële ondersteuning: geen gemeld
}

\section{Summary}

There is general consensus that the development of empathy and medical professionalism should have high priority in medical education. Teaching students how to empathise with patients with mental illness poses an extra challenge. Students have been shown to have attitudes towards mental illness that are characterised by prejudice and stigmatisation. This is worrisome, as in their future practice most students are likely to encounter not only patients but also colleagues with mental illness. Prejudice and stigmatisation may result in inadequate care. This article describes an educational session in which medical students are confronted with a student who talks about his mental illness. The aim of the session is to bridge the gap between medical students and patients with a mental illness. (Gosselink MJ, Fenema EM van. Medical students encounter a student with mental illness: promoting empathy. Netherlands Journal of Medical Education 2011;30(1-2):22-27) 